\title{
CHEWING EFFICIENCY WITH DIFFERENT TYPES OF BAR JOINT USED TO RETAIN MANDIBULAR IMPLANT OVERDENTURES. A CROSS OVER STUDY
}

\author{
Mostafa A.Y. Hammas*
}

\begin{abstract}
Objectiv: This article aimed to evaluate, within patient, the chewing efficiency with different types of bar joint used to retain mandibular implant overdentures .

Materials and methods: ten (5 males and 5 females) completely edentulous patients (mean age is 59 years old) received maxillary and mandibular conventional dentures (control group, GI). After, 3 months of adaptation, 2 implants were inserted in the mandibular canine areas. In a quasirandom method, implants were connected with either Dolder (group II, GII) or Hader (Group III, GIII) bars and patient received mandibular implant overdentues. Chewing efficiency was measured using a 2-colored chewing gum after 5, 10, 20, 30 and 50 chewing cycles. Measurements were made 3 months after wearing the following prostheses; new conventional dentures, Dolder bar/ implant retained overdentures and Hader bar/implant retained overdentures.
\end{abstract}

Results: Regardless the number of chewing strokes, GI recorded the highest UF and GIII recorded the lowest UF. GI recorded the significant higher UF compared to GII and GIII. GIII showed significant higher UF than GII. Regardless the group, 5 strokes recorded the highest UF and 50 strokes showed the lowest UF.

Conclusion: within limitations of this cross-over study, bar/implant retained overdentures are associated with improved chewing efficiency compared to conventional dentures. Dolder bar used to retain mandibular implant overdentures showed significant increase in chewing efficiency compared to Hader bar.

KEYWORDS: chewing efficiency, bar joint, mandibular overdentures Dolder bar, Hader bar.

\section{INTRODUCTION}

Edentulism leads to a definite impairment of oral function with both aesthetic and psychological changes. Functional problems associated with edentulism, such as poorly retained dentures and diminished chewing efficiency are widely reported ${ }^{(1)}$.

* Assistant Professor and Acting Head of Prosthodontics Department, Faculty of Dental Medicine, Al-Azhar University, Assuit branch 
Overdentures in the mandible supported by two implants placed in the interforaminal region have been well documented in clinical investigations and have been suggested as standard treatment for the edentulous patient ${ }^{(2)}$. Such prosthesis is an attractive treatment because of its relative simplicity, minimal invasiveness, and economy ${ }^{(3)}$. Furthermore, some studies $^{(4-6)}$ have shown high success rate for twoimplant-retained mandibular overdenture. Three basic types of attachments are commonly used: resilient studs, bar/clip devices, and magnets. ${ }^{(7)}$

Bar attachments provide several advantages such as primary splinting, stress distribution between implants -especially in immediately loaded implants- ${ }^{(8)}$ and horizontal stability in case of advanced degree of atrophy ${ }^{(9)}$. As well as possibility to be used when implants are angulated ${ }^{(10)}$ and provision for different degrees of rotational and vertical movement towards the tissue -depending on the specific cross-sectional shape-(11). However, bar and clip attachments need more restorative space, are initially more expensive, and are technically more complex than stud attachments. ${ }^{(12,13)}$ They also need a space between the bar and the mucosa to facilitate oral hygiene of the proximal surfaces of the implants. ${ }^{(14)}$

Bar attachments are classified into two groups: bar joint and bar unit.(15) Bar joint allows some degree of movements around the bar during mastication. Frederick and Caputo ${ }^{(16)}$ stated that; spaced oval or round bars allow both vertical and rotational movements. The Dolder bar joint is egg shaped, a spacer is placed between the bar and the sleeve, this will allow the sleeve to have vertical as well as rotations movement around the bar, and thus become a resilient attachment. At position of rest the denture rest on the ridges and is completely tissue born, the sleeve is about $1 \mathrm{~mm}$ above the crest of the bar and during function Dolder bar joint allow vertical translation, frontal and sagittal rotation $^{(17)}$ The Hader bar system is only $3 \mathrm{~mm}$ high.
It has a round superior aspect and an apron toward the tissue below. It consists of a key hole shaped male bar resin pattern, Teflon fabricating rider, and female nylon rider clip. ${ }^{(18)}$

There are two types of bar joint which are single sleeve bar joint and multiple sleeve bar joint. Dolder bar joint is an example for single sleeve bar joint. ${ }^{(19)}$ Walton and Ruse ${ }^{(20)}$ stated that; short sleeves may be constructed either from metal or plastic types. Plastic (Hader system) are more easily replaced if retention has slackened, less expensive, and it may produce less wear of the metal bar than metal clips. However, plastic clips cannot be adjusted.

Stabilization of the occlusion by means of implant supported dentures in the edentulous jaws has shown considerable improvement of the masseter muscle activity(21) and jaw movements thus providing improved chewing function and comfort ${ }^{(21-25)}$ compared with conventional complete dentures. Moreover, implant stabilized overdentures improve maximum bite force and masticatory performance, improve patient satisfaction and minimize pain during chewing (26,27). A study (28) reported that; the implant supported overdenture loses only $10 \%$ of chewing efficiency compared with natural teeth. It may be assumed that an implant-supported overdenture is no less efficient than a fixed prosthesis with respect to masticatory function

Several methods of objective estimation of masticatory efficiency have been used in previous studies, including the sizes of chewed particles, maximum biting force ${ }^{(29)}$, mastication time, total number of masticatory cycles ${ }^{(28,30)}$, sieving method and two-colour chewing gum. ${ }^{(31,32)}$

The improvement of chewing effeciency may depend on the amount of retention and stability of the denture and thus on the type of retention mechanism ${ }^{(33,34)}$. Differenct types of bars provide varying degrees of retention and stability. Which may affect masticatory effeciency. Therfore the 
aim of the present study was to evaluate, within patient, the chewing efficiency with different types of bar joint used to retain mandibular implant overdentures.

\section{MATERIALS AND METHODS}

\section{Patient enrollment}

Ten (5 males and 5 females) patients with completely edentulous maxillary and mandibular ridges (mean age is 59 years old) participated in this study. Subjects were included in this study provided that they had normal mucosa, adequate inter-ridge space, class III to class V resorption in the anterior region of the mandible according to Cawood and Howell ${ }^{(35)}$, and good bone quality (classes 1-3 according to Lekholm and Zarb) ${ }^{(36)}$. All participants were unsatisfied with their mandibular dentures due to reduced stability and insufficient retention.

Exclusion criteria include any systemic diseases that may affect the prognosis of implant treatment such as diabetes, smoking habit, osteoporosis, immune deficiency, radiotherapy to the head and neck region and anticoagulant therapy. The subjects were provided with sufficient details about the study out lines and a written informed consent was obtained from each patient. The study was conducted according to the ethical guidelines reported in the Helsinki Declaration for clinical trials.

\section{Surgical and prosthetic procedures}

All participants received new maxillary and mandibular complete dentures (Control group, CD) constructed according to the conventional denture fabrication procedures ${ }^{(37)}$. Preliminary impressions were made and custom autopolymerizd acrylic resin tray fabricated from the study cast was border molded and the final impressions were made with non-eugenol zinc oxide paste (Cavex, Holland and IRM, Dentsply, USA). Jaw relations were performed. Semi-anatomic acrylic resin teeth (Vitapan ${ }^{\circledR, V i t a ~}$ Zahnfabrik, Bad Säckingen, Germany) were arranged in bilateral balanced occlusion. The patients were informed to use the new dentures for 3 months to increase neuro-muscular adaptation, then the chewing efficiency was measured

Each patient received two interforaminal implants implants (Zimmer Inc., TSV, Carlsbad, CA. USA) in the canine region of the mandible using conventional 2- stage surgical approach by the same oral and maxillofacial surgeon. After 3 months osseointegration period, second stage surgery was performed and healing abutments were connected to the implants.

Preliminary mandibular impressions were made and custom autopolymerizd acrylic resin tray fabricated with holes above the implants. Open tray impression was made to the lower ridge. The trays were border molded and secondary impressions were made using non-eugenol zinc oxide paste. Excess zinc oxide impression was removed from the opening of the trays; long transfer impression copings were screwed in the internal hex of the implants. Light body rubber base impression material was injected around the copings wile applying hand pressure on the distal portions of the tray. Self-cure acrylic resin was used to pick-up the transfer coping to the polished surface of the trays. The copings were unthreaded and implant analogues were connected to the copings and the impression was poured in stone. On the resultant cast, bar abutments were tightened to implant analogues at $25 \mathrm{Ncm}$ torque.

In a quasi-random method 5 patients received Dolder bar-retained implant overdentures (group II, GII, fig 1) first and after 3 months of adaptation, the chewing efficiency was measured, then the patients received Hader bar-retained implant overdentures (group III, GIII, fig 2). The other 5 patients received Hader bar-retained implant overdentures first, and after 3 months of adaptation, the chewing efficiency was measured, then the patients received Dolder bar-retained implant overdentures. 


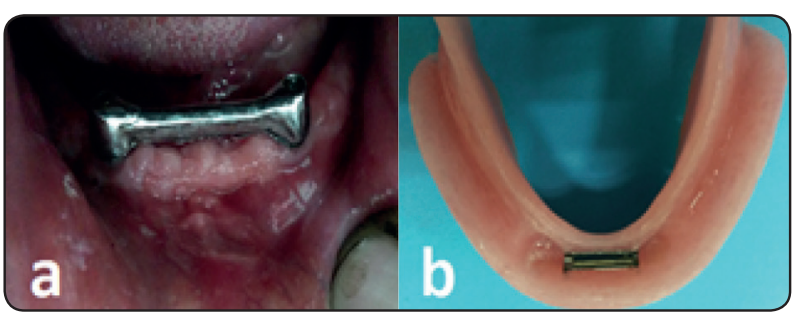

Fig. (1) a; Dolder bar (GII) intra-oral view. b; fitting surface with Dolder bar-clip

For group II, titanium caps of bar abutments were tightened to bar abutments. The Dolder bar (ovoid cross section, titanium made, Resilient bar rematitan $\mathrm{R}$, macro, height $3.0 \mathrm{~mm}$, TioLogic, Dentaurum, Germany) was sectioned and laser welded to the titanium caps. For group III, the plastic portion of Hader bar (round cross section, Resilient OT bar ®), height $3.0 \mathrm{~mm}$, RHEIN 83, Italy) was cut and luted to the plastic portions of bar abutments and the assembly were casted in cobalt chromium alloy. For both groups a space of $1.5-2 \mathrm{~mm}$ clearance between the bar and the ridge was provided for oral hygiene purposes. The bars were tried in for passive fit intraorally.

The polished and occlusal surfaces of mandibular existing dentures were replicated using a silicone $\operatorname{mold}^{(38)}$. The mold was repositioned against the final casts to produce 2 duplicate mandibular dentures of the same contour. The existing maxillary dentures were used for all groups. For group II (Doder bar), a single titanium sleeve (Bar rider and retention rematitanR) was used. Acrylic resin retention tags were welded to the sleeve of the bar. For group II, 2 metal riders of plastic clips (medium retention) were used. Dentures were processed in usual manners, finished, polished and inserted. Patients were recalled for adjustments of dentures base and refining the occlusion by selective grinding in centric and eccentric positions.

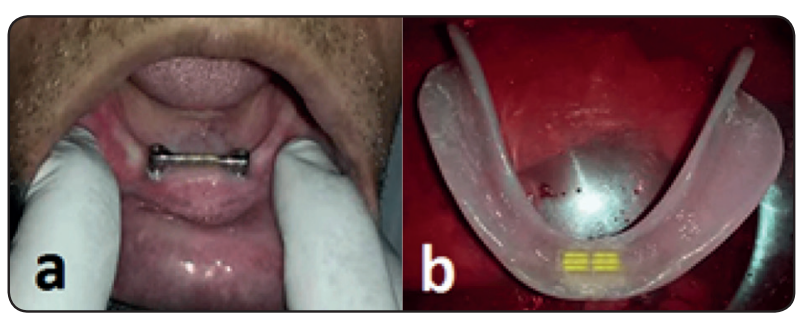

Fig. (2) a; Hader bar (GIII) intra-oral view. b; fitting surface with Hader bar-clips

\section{Measurement of masticatory efficiency}

Masticatory efficiency was measured 3 months after wearing each of the following prosthesis; conventional dentures (GI), Dolder bar-implant overdentures (GII) and Hader bar-implant overdentures (GIII).

Measurement of masticatory efficiency was performed using the 2-colored gum mixing ability test ${ }^{(31,32)}$. Two pieces $(303 \times 18 \times \mathrm{mm})$ in size of Gum of 2 colors; one with the taste 'mint flavor' (white color) and the other with the taste 'Strawberry Fruit' (red color) were staked together. The subjects were informed to masticate 5 samples of gum for 5 , 10, 20, 30 and 50 cycles respectively. One minute intervals were allowed between each chewing strokes to eliminate muscle fatigue.

The chewed gums were spat and flattened to $1 \mathrm{~mm}$ thickness in nylon transparent bags. The gums were then scanned from both sides with a of resolution 600 dots per inch (fig3). The scanned image was copied into an image of fixed size $(1175 \times 925$ pixels) and stored in Adobe Photoshop ${ }^{\circledR}$ format (*.psd). Then the 'magic wand' tool (tolerances $20,25,30)$ and "histogram" function were used to select the unmixed orange parts of the image. The numbers of selected pixels were recorded from the histogram for each side and mean of those figures was calculated. Subsequently a ratio was computed for the Unmixed Fraction (UF) using the following formula: 


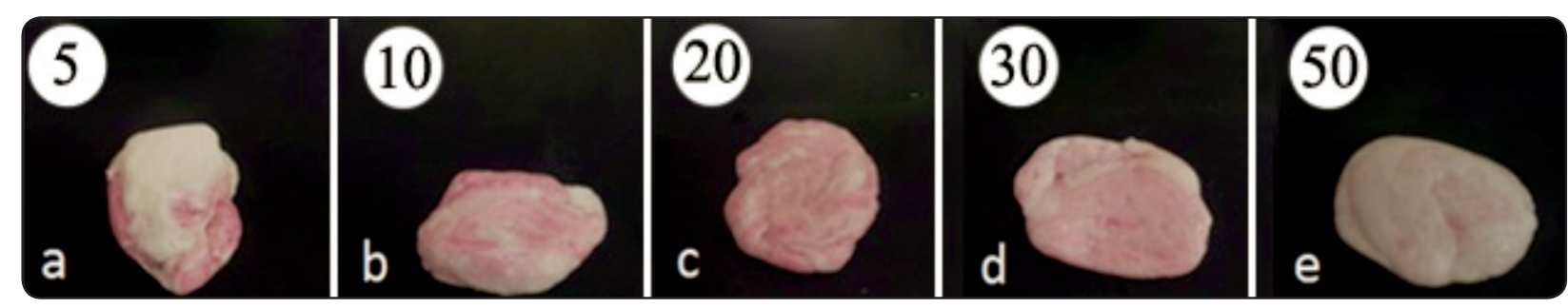

Fig. (3) Colored gum mixed after 5 (a), 10(b), 20 (c), 30 (d), and 50 (e) chewing cycles.

The increased UF means a decrease in chewing efficiency and vice versa. To assess the reproducibility of chewing, the subjects were available to repeat the experiments on a different day.

\section{Statistical analysis:}

The assumption of the normality of the collected data was tested by Shapiro-Wilk test. The data was parametric and meet the normal distribution. To compare UF values between groups (conventional dentures and Dolder bar implant overdentures and Hader bar implant overdentures) and between different chewing cycles $(5,10,20,30$ and 50 cycles), 2 way repeated measures ANOVA was used by Tukey test for post-hoc test . Statistical significance was set at .05 for all analyses.

\section{RESULTS:}

Descriptive statistics and comparison of chewing efficiency (UF) between different groups and between different number of chewing cycles is presented in table 1 . There was a significant difference in UF between groups (Repeated ANOVA, $\mathrm{p}=.00$ ) and between number of chewing strockes (Repeated ANOVA, p=.00), and the interaction between groups and chewing strokes was also significant $(\mathrm{p}=.00)$. Regardless the number of chewing strokes, there was a significant differece in UF between each 2 groups with GI recorded the highest UF and GIII recorded the lowest UF. GI recorded the significant higher UF compared to GII and GIII (tukey test, $\mathrm{p}<.001$ ). GIII showed significant higher UF than GII (tukey test, $\mathrm{p}<.001$ ). Multiple comparison between each 2 groups at different number of chewing strokes is presented in table 2. There was no significant difference in UF between GI and GIII at 5 strokes. Also no significant difference between GII and GIII at 10 and 20 chewing strokes was detected.

Comparison of different numbers of chewing strokes is presented in table 1. Regardless the group, 5 strokes recorded the highest UF and 50 strokes showed the lowest UF(tukey test, $\mathrm{p}<.001$ ). Multiple (post hoc comparisons) between chewing strokes are presented in the same tabe. There was a singificant differerce between each 2 numbers of chewing strokes except 5 and 10 chewing strokes which demonestrated insignificant difference in between. For GI no significant difference in UF between 5 and 10 strokes nor between 20 and 30 strokes. For GII, and GIII, no significant difference in UF between 5 and 10 strokes. All other chewing strokes demonestrated significant differences in between. 
TABLE (1) Descriptive statistics and comparison of chewing efficiency (UF) between different groups with different number of chewing cycles.

\begin{tabular}{|c|c|c|c|c|c|}
\hline & & $\begin{array}{c}\text { Conventional } \\
\text { dentures }\end{array}$ & $\begin{array}{c}\text { Hader bar-implant } \\
\text { overdentures }\end{array}$ & $\begin{array}{c}\text { Dolder bar-implant } \\
\text { overdentures }\end{array}$ & $\begin{array}{c}\text { Repeated measures } \\
\text { ANOVA }\end{array}$ \\
\hline \multirow{5}{*}{5 strokes } & Mean & $.690280 \mathrm{~A}$ & $.623480 \mathrm{~A}$ & $.617420 \mathrm{~A}$ & \multirow{5}{*}{$\mathrm{P}<.001 *$} \\
\hline & Median & .689800 & .621300 & .617100 & \\
\hline & $S D$ & .0064577 & .0048438 & .0011323 & \\
\hline & Min & .6821 & .6199 & .6160 & \\
\hline & $\operatorname{Max}$ & .6985 & .6313 & .6190 & \\
\hline \multirow{5}{*}{10 strokes } & Mean & $.687220 \mathrm{~A}$ & $.617480 \mathrm{~A}$ & $.598540 \mathrm{~A}$ & \multirow{5}{*}{$\mathrm{P}<.001 *$} \\
\hline & Median & .686500 & 619500 & .599900 & \\
\hline & $S D$ & .0075860 & .0038154 & .0025687 & \\
\hline & Min & .6777 & .6112 & .5948 & \\
\hline & $\operatorname{Max}$ & .6987 & .6202 & .6010 & \\
\hline \multirow{5}{*}{20 strokes } & Mean & $.672180 \mathrm{~B}$ & $.604600 \mathrm{~B}$ & $.598540 \mathrm{~B}$ & \multirow{5}{*}{$\mathrm{P}<.001 *$} \\
\hline & Median & .672000 & .605000 & .599900 & \\
\hline & $S D$ & .0023167 & .0040373 & .0025687 & \\
\hline & Min & .6699 & .6000 & .5948 & \\
\hline & $\operatorname{Max}$ & .6751 & .6090 & .6010 & \\
\hline \multirow{5}{*}{30 strokes } & Mean & $.669800 \mathrm{~B}$ & $.595840 \mathrm{C}$ & $.570460 \mathrm{C}$ & \multirow{5}{*}{$\mathrm{P}<.001 *$} \\
\hline & Median & .670000 & .595000 & .581000 & \\
\hline & $S D$ & .0121977 & .0038214 & .0254629 & \\
\hline & Min & .6535 & .5912 & .5250 & \\
\hline & $\operatorname{Max}$ & .6832 & .6000 & .5843 & \\
\hline \multirow{5}{*}{50 strokes } & Mean & $.647960 \mathrm{C}$ & $.559400 \mathrm{D}$ & $.521500 \mathrm{D}$ & \multirow{5}{*}{$\mathrm{P}<.001 *$} \\
\hline & Median & 649900 & .559500 & .520000 & \\
\hline & $S D$ & .0067648 & .0036980 & .0049122 & \\
\hline & Min & .6400 & .5550 & .5150 & \\
\hline & $\operatorname{Max}$ & .6566 & .5650 & .5276 & \\
\hline \multicolumn{2}{|c|}{$\begin{array}{l}\text { Repeated measures } \\
\text { ANOVA }\end{array}$} & $\mathrm{P}<.001 *$ & $\mathrm{P}<.001 *$ & $\mathrm{P}<.001 *$ & \\
\hline
\end{tabular}

SD; Standard Deviation, Min; minimum, Max; maximum. * p is significant at $5 \%$ level. Different letters in the same column indicated a significant difference between numbers of chewing strokes (post-hoc tukey test, $p<.05$ ) 
TABLE (2) mutliple comparison beween differenct typed of prosthesis (groups). Number in each cell indicates the $\mathrm{p}$ value of tukey post-hoc test

\begin{tabular}{|c|c|c|c|}
\hline & $\begin{array}{c}\text { Conventional- } \\
\text { Dolder bar }\end{array}$ & $\begin{array}{c}\text { Conventional- } \\
\text { Hader bar }\end{array}$ & $\begin{array}{c}\text { Dolder bar- } \\
\text { Hader Bar }\end{array}$ \\
\hline 5 strokes & $<.001 *$ & .261 & $<.001 *$ \\
\hline 10 strokes & $<.001 *$ & $<.001 *$ & .324 \\
\hline 20 strokes & $<.001 *$ & $<.001 *$ & .260 \\
\hline 30 strokes & $<.001 *$ & $<.001 *$ & $<.001 *$ \\
\hline 50 strokes & $<.001 *$ & $<.001 *$ & $<.001 *$ \\
\hline
\end{tabular}

*p is significant at $5 \%$ level

\section{DISCUSSION}

Chewing efficiency depends mainly on food comminutions, therefore it depends on within patient anatomical factors such as activity and tonicity of muscles of mastication, jaw relations and ridge anatomy. Other sociodemographic data of the patients such as age and gender also may affect the muscle activity and masticatory efficiency. Therefore the cross over design used in this study helped to standardize these factors and make the measurements of chewing efficiency more reliable ${ }^{31}$. Furthermore, duplication of the occlusal and polished surface of the conventional dentures into implant overdentures ensure rapid patient adaptation and eliminate any prosthetic factors and may affect the masticatory efficiency. Colored chewing gum was used to evaluate masticatory efficiency based on recommendations of several previous studies ${ }^{(31,32,39)}$. The gum has several merits such as availability, simplicity and cost effectiveness in comparison to other methods used to evaluate chewing efficiency. Moreover, the increased color mixing indicates higher chewing efficiency because the color mixing resulted from extraction and leaching out of the sweetening components. In addition, the use of chewing gum does not allow stagnation of food particles under the dentures or swallowing of these particles and thus may be lost and not evaluated ${ }^{(40)}$.
The chewing efficiency increased (UF decreased) with increased numbers of chewing cycles. This was not surprising because it indicates a higher degree of color mixture, leaching out of sweetening components and increased mixing ability of the patients ${ }^{(32)}$. The same result was also obtained in another within patient-study ${ }^{(31)}$ in which the authors compared chewing efficiency and electromyographic activity of 3 attachments used for mandibular implant overdentures.

The increased chewing efficiency with implant overdentures (regardless the bar type) compared to conventional dentures agrees with the findings of many authors ${ }^{(34,41,43)}$ and may be attributed to the improved stability and retention of conventional dentures by osseointegrated implants. It is well known that conventional denture wearers have impaired masticatory function, including lower maximum voluntary bite forces and lower levels of muscular effort during maximum clenching and mastication ${ }^{(44,45)}$. This could be attributed to denture instability probably prevents denture wearers from using the full potential of their jaw muscles, especially during unilateral biting and chewing ${ }^{(46)}$. In contrast, full prostheses supported by osseointegrated implants in edentulous mandibles has shown considerable improvement in muscular activity and mandibular movements, mainly because of their association with a more stabilized occlusion, satisfaction and comfort of patients ${ }^{(21)}$. Moreover, implant stabilized overdentures, elevate bite force and chewing performance, improve patient satisfaction and decrease discomfort during chewing $^{(26,27)}$. In a within-subject clinical trial,Elsyad et $\mathrm{al}^{(31)}$. found that 2-implant retained overdentures with either ball or Hader bar attachments showed a significant increase in chewing efficiency and electromyographic activity when compared to conventional dentures.

The increased chewing efficiency with Dolder (oval) bars was significantly higher than Hader 
(round) bar. This may be attributed to the increased retention and stability provided by Dolder bar compared to Hader bar. The Dolder bar is made of titanium and had a long titanium sleeve which aid in retention and stability of the overdentures and as it is less subjected to wear. In line with this explanation, Saito et.al. ${ }^{(47)}$ reported that the retention force titanium Dolder bars with metal clips did not changes after repeated insertions and removals of the dentures. They also noted an increase in retention forces with rounded cobalt chromium and titanium bars and gold clips after wear simulation. They recommend the use of round and Dolder bars made from cobalt chromium and titanium with metal clips over a long term for 2-implant overdentures because their retentive force tended to increase. ${ }^{(47)}$ on the other hand plastic clips of Hader bar are subjected to wear during the 3 months adaptation period. Therefore, it provides less stability and retention compared to Dolder bar. In agreement with this justification, Doukas, et al. ${ }^{(48)}$ noted that red and yellow plastic clips of Hader bars were affected by wear following 6-month simulated clinical use compared to ball and magnet attachments. Although 2 clips were used to control lateral movements and to minimize wear of plastic clips, the stability of Dolder bar attachment system seems to be better. In agreement with these observations Savabi, et al.(49) also noted that, the highest average value retention was recorded for the single or cantilevered Dolder bar (with one or 3 metal clips) in both the vertical and posteroanterior directions. On the other, hand the lowest retention was noted with Hader bar with Rhein pink caps in the posteroanterior direction.

\section{CONCLUSION}

Within limitations of this cross-over study, bar/implant retained overdentures are associated with improved chewing efficiency compared to conventional dentures. Dolder bar used to retain mandibular implant overdentures showed significant increase in chewing efficiency compared to Hader bar.

\section{REFERENCES}

1. Zarb G, Mericske-Stern R. Clinical protocol for treatment with implant supported over dentures. . 509-498:2004.

2. Bernhart G, Koob A, Schmitter M, Gabbert O, Stober T, Rammelsberg P. Clinical success of implant-supported and tooth-implant-supported double crown-retained dentures. Clin Oral Investig. 7-16:1031;2012.

3. Klemetti E, Lassila L, Lassila V. Biometric design of complete dentures related to residual ridge resorption. J Prosthet Dent. 4-75:281;1996.

4. Jemt T, Chai J, Harnett J, Heath MR, Hutton JE, Johns RB, et al. A -5year prospective multicenter follow-up report on overdentures supported by osseointegrated implants. Int J Oral Maxillofac Implants. 8-11:291;1996.

5. Naert I, Gizani S, Vuylsteke M, Van Steenberghe D. A -5year prospective randomized clinical trial on the influence of splinted and unsplinted oral implants retaining a mandibular overdenture: prosthetic aspects and patient satisfaction. J Oral Rehabil. 202-26:195;1999.

6. Mericske-Stern R, Steinlin Schaffner T, Marti P, Geering AH. Peri-implant mucosal aspects of ITI implants supporting overdentures. A five-year longitudinal study. Clin Oral Implants Res. 18-5:9;1994.

7. Tokuhisa M, Matsushita Y, Koyano K. In vitro study of a mandibular implant overdenture retained with ball, magnet, or bar attachments: comparison of load transfer and denture stability. Int J Prosthodont. 34-16:128;2003.

8. Elkerdawy MW, Radi IA. Effect of dislodging forces on mandibular implant attachment-retained overdenture. Implant Dent. 54-20:246;2011.

9. Heckmann SM, Winter W, Meyer M, Weber HP, Wichmann MG. Overdenture attachment selection and the loading of implant and denture-bearing area. Part 1: In vivo verification of stereolithographic model. Clin Oral Implants Res. 23-12:617;2001.

10. Schneider AL, Kurtzman GM. Restoration of divergent free-standing implants in the maxilla. J Oral Implantol. 6-28:113;2002.

11. Al-Ghafli SA, Michalakis KX, Hirayama H, Kang K. The in vitro effect of different implant angulations and cyclic dislodgement on the retentive properties of an overdenture attachment system. J Prosthet Dent. 7-102:140;2009.

12. Sadowsky SJ. Mandibular implant-retained overdentures: a literature review. J Prosthet Dent. 73-86:468;2001. 
13. Burns DR. Mandibular implant overdenture treatment: consensus and controversy. J Prosthodont. 46-9:37;2000.

14. Efvinol. B, Jorgeusen. D. Prosthetic for elderly. Quintessence, Publication Co. Inc.Chicago. . 1999:P233.

15. Aydin M, Yilmaz A, Katiboglu B, Tunc EP. ITI implants and Dolder bars in the treatment of large traumatic defect of mandible: a clinical report. Dental traumatology : official publication of International Association for Dental Traumatology. 52-20:348;2004.

16. Federick DR, Caputo AA. Effects of overdenture retention designs and implant orientations on load transfer characteristics. J Prosthet Dent. 32-76:624;1996.

17. Dolder EJ, Durr GT. The bar joint denture. . Quintessence Puplishing Co Chicago, Berlin, Roide, Janeiro and Tokyo Inc 1978.1978 .

18. Rudd K, Morrow R, HF E. Dental laboratory procedures: Removable partial denture. The C.V. Mosby Company St. Louis. Toronto. London. 1981.

19. Preiskel HW, Arvidson K, Geering AH, Mericske-Stern R. Overdentures Made Easy: A Guide to Implant and Root Supported Prostheses. London:. Quintessence Int. 32-89:212;1996.

20. Walton JN, Ruse ND. In vitro changes in clips and bars used to retain implant overdentures. J Prosthet Dent. 6-74:482;1995.

21. Karkazis HC. EMG activity of the masseter muscle in implant supported overdenture wearers during chewing of hard and soft food. J Oral Rehabil. 91-29:986;2002.

22. Jemt T, Lindquist L, Hedegard B. Changes in chewing patterns of patients with complete dentures after placement of osseointegrated implants in the mandible. J Prosthet Dent. 83-53:578;1985.

23. Jemt T, Stalblad PA. The effect of chewing movements on changing mandibular complete dentures to osseointegrated overdentures. J Prosthet Dent. 61-55:357;1986.

24. Haraldson T, Carlsson GE, Ingervall B. Functional state, bite force and postural muscle activity in patients with osseointegrated oral implant bridges. Acta odontologica Scandinavica. 206-37:195;1979.

25. van Kampen FM, van der Bilt A, Cune MS, Bosman F. The influence of various attachment types in mandibular implant-retained overdentures on maximum bite force and EMG. J Dent Res. 3-81:170;2002.
26. Slagter AP, Bosman F, van der Glas HW, van der Bilt A. Human jaw-elevator muscle activity and food comminution in the dentate and edentulous state. Archives of oral biology. 205-38:195;1993.

27. Diaz-Tay J, Jayasinghe N, Lucas PW, McCallum JC, Jones JT. Association between surface electromyography of human jaw-closing muscle and quantified food breakdown. Archives of oral biology. 8-36:893;1991.

28. Feine JS, Maskawi K, de Grandmont P, Donohue WB, Tanguay R, Lund JP. Within-subject comparisons of implant-supported mandibular prostheses: evaluation of masticatory function. J Dent Res. 56-73:1646;1994.

29. Schimmel M, Leemann B, Herrmann FR, Kiliaridis S, Schnider A, Muller F. Masticatory function and bite force in stroke patients. J Dent Res. 4-90:230;2011.

30. Feine JS, Lund JP. Measuring chewing ability in randomized controlled trials with edentulous populations wearing implant prostheses. J Oral Rehabil. -33:301;2006 8.

31. Elsyad MA, Hegazy SA, Hammouda NI, Al-Tonbary GY, Habib AA. Chewing efficiency and electromyographic activity of masseter muscle with three designs of implantsupported mandibular overdentures. A cross-over study. Clin Oral Implants Res. 8-25:742;2014.

32. Schimmel M, Christou P, Herrmann F, Muller F. A twocolour chewing gum test for masticatory efficiency: development of different assessment methods. J Oral Rehabil. 8-34:671;2007.

33. van der Bilt A, van Kampen FM, Cune MS. Masticatory function with mandibular implant-supported overdentures fitted with different attachment types. Eur J Oral Sci. 6-114:191;2006.

34. van Kampen FM, van der Bilt A, Cune MS, FontijnTekamp FA, Bosman F. Masticatory function with implantsupported overdentures. J Dent Res. 11-83:708;2004.

35. Cawood JI, Howell RA. A classification of the edentulous jaws. Int J Oral Maxillofac Surg. 6-17:232;1988.

36. Lekholm U, Zarb G. Patient selection and preparation. In: Branemark PI, Zarb G, Albrektsson T, eds. Tissue integrated prosthesis: osseointegration in clinical dentistry. Chicago. Quintessence Publishing Co Inc. 209-1985:199.

37. Zarb G,Bolender C, Eckert S, Jacob R, Fenton A, MericskeStern R. Prosthodontic treatment for edentulous patients: complete dentures and implant-supported prostheses. 12th ed St Louis: Mosby. 2003:p. 425-211. 
38. Elsyad MA, El-Waseef FA, Al-Mahdy YF, Fouad MM. A comparison of mandibular denture base deformation with different impression techniques for implant overdentures. Clin Oral Implants Res. 24;2013 Suppl A33-100:127.

39. Anastassiadou V, Heath MR. The development of a simple objective test of mastication suitable for older people, using chewing gums. Gerodontology. 86-18:79;2001.

40. Liedberg B, Owall B. Oral bolus kneading and shaping measured with chewing gum. Dysphagia. 6-10:101;1995.

41. van der Bilt A, Speksnijder CM, de Liz Pocztaruk R, Abbink JH. Digital image processing versus visual assessment of chewed two-colour wax in mixing ability tests. J Oral Rehabil. 7-39:11;2012.

42. Bakke M, Holm B, Gotfredsen K. Masticatory function and patient satisfaction with implant-supported mandibular overdentures: a prospective -5year study. Int J Prosthodont. 81-15:575;2002.

43. Toman M, Toksavul S, Saraçog `lu A, Cura C, Hatipog `lu A. Masticatory Performance and Mandibular Movement Patterns of Patients with Natural Dentitions, Complete Dentures, and Implant-Supported Overdentures. . Int J Prosthodont 7-25:135;2012.
44. Slagter AP, Bosman F, Van der Bilt A. Comminution of two artificial test foods by dentate and edentulous subjects. J Oral Rehabil. 76-20:159;1993.

45. Fontijn-Tekamp FA, Slagter AP, Van Der Bilt A, Van THMA, Witter DJ, Kalk W, et al. Biting and chewing in overdentures, full dentures, and natural dentitions. J Dent Res. 24-79:1519;2000.

46. Caloss R, Al-Arab M, Finn RA, Throckmorton GS. The effect of denture stability on bite force and muscular effort. J Oral Rehabil. 9-38:434;2011.

47. Saito M, Kanazawa M, Takahashi H, Uo M, Minakuchi S. Trend of change in retentive force for bar attachments with different materials. J Prosthet Dent. 52-112:1545;2014.

48. Doukas D, Michelinakis G, Smith PW, Barclay CW. The influence of interimplant distance and attachment type on the retention characteristics of mandibular overdentures on 2 implants: -6month fatigue retention values. Int J Prosthodont. 4-21:152;2008.

49. Savabi O, Nejatidanesh F, Yordshahian F. Retention of implant-supported overdenture with bar/clip and stud attachment designs. J Oral Implantol. 7-39:140;2013. 